\title{
Uma experiência com a Linguagem Scratch no Ensino de Programação com Alunos do Curso de Engenharia Elétrica.
}

\author{
Jadson do Prado Rafalski, Otávio Lube dos Santos \\ Departamento de Informática - Universidade Federal do Espírito Santo \\ (UFES) \\ Av. Fernando Ferrari, 514, Goiabeiras - Vitória - ES - CEP 29075-910 \\ jrafalski@inf.ufes.br, olube@inf.ufes.br
}

\begin{abstract}
The programming education is one of the great challenges in higher education. Motivating students is not always a trivial task, especially when it is a "barrier" in computing and engineering courses. Under this assumption, this article aims to expose the benefits of Scratch programming tool in teaching making a playful manner through the development of digital games. To contribute to the academic world this discussion, this paper propose an experience gained during the course of introduction to programming an electrical engineering course in a private college of Vila Velha/ES. The results were satisfactory since the classes were more interactive and enjoyable for students.
\end{abstract}

Resumo. O ensino de programação é um dos grandes desafios no ensino superior. Motivar os estudantes nem sempre é uma tarefa trivial, ainda mais quando se trata de uma "barreira" nos cursos de computação e engenharia. Partindo deste pressuposto, este artigo visa expor os benefícios da ferramenta Scratch no ensino de programação tornando de maneira lúdica por meio do desenvolvimento de jogos digitais. Visando contribuir para o meio acadêmico essa discussão, este trabalho propõem uma experiência obtida durante a disciplina de introdução à programação de um curso de engenharia elétrica de uma faculdade particular de Vila Velha/ES. Os resultados obtidos foram satisfatórios já que as aulas foram mais interativas e agradáveis aos estudantes.

\section{Introdução}

Programação de computadores é uma disciplina que nem sempre os estudantes iniciantes dos cursos de computação têm facilidade, sendo uma área em potencial para pesquisas. Uma das dificuldades dos estudantes ao aprender programação é o fator tempo, uma vez que, em um curto espaço de tempo diversos conceitos como algoritmos, estruturas de controle, estruturas de decisão, estruturas de dados e linguagens de programação, todas essas são apresentadas para o aluno durante o período do curso. Tais estruturas são importantes com o objetivo de desenvolver pensamento e habilidades específicas na área computacional (Kölling et al., 1995).

Por outro lado, ainda há a questão de motivação para a aprendizagem de programação, segundo (Jenkins, 2001) a motivação para o aluno aprender programação está na realização de uma dinâmica que esteja diretamente relacionada com a área da sua 
formação para que tenha capacidade de visualizar de maneira transparente a importância do conhecimento para sua formação.

Neste contexto, os jogos digitais podem ser elementos motivadores para o processo de ensino-aprendizado em programação. Desenvolver jogos digitais permite que o jogador reflita e encontre soluções constantemente para diversas situações que os jogos propõem. Os jogos exercitam o uso da intuição do jogador, assim como a reflexão e a adaptação de uma situação-problema a outra similar, transferindo o conhecimento anteriormente adquirido para aplicar em novas situações, ou seja, o jogador, com suas práticas, aprende a aprender, necessita pensar e refletir sobre os acontecimentos do jogo e seus objetivos, aprendizado que pode ser estendido às práticas em outras situações (Gee, 2009).

Para PIAGET (1951), o jogo é fator de grande importância no desenvolvimento cognitivo. Além disso, os jogos são provedores de conhecimento e motivadores para o aprendizado levando o sujeito a ser capaz de tomar decisões, de fazer escolhas, de trabalhar na solução de problemas com autonomia (Gee, 2003), o que o torna mais envolvido nos desafios que são propostos pelos jogos e, consequentemente, ele é motivado a desenvolver as tarefas para alcançar o seu objetivo (Prensky, 2003).

Dentro deste contexto, o Scratch (Scratch, 2016), possui uma grande facilidade que permite o desenvolvimento de jogos e animações, ou seja, as pessoas passam a serem protagonistas e não somente usuários desta tecnologia (Maloney et al., 2010).

Considerando as possibilidades da ferramenta Scratch, foi realizado um trabalho durante a disciplina de introdução à programação com uma turma de Engenharia Elétrica do primeiro período no munícipio de Vila Velha no Espírito Santo, Brasil. O objetivo deste trabalho foi aprender a pensar de forma criativa, refletir de maneira sistêmica e trabalhar de modo colaborativo. Foi proposto para a turma $o$ desenvolvimento de um jogo que poderia ser utilizado na área da Engenharia Elétrica. $\mathrm{O}$ presente trabalho teve o propósito de apresentar a comunidade em geral como o Scratch pode ser uma ferramenta para auxiliar as disciplinas que envolvam programação computacional.

Este artigo está organizado como se segue: Na seção 2 é apresentada a ferramenta utilizada o Scratch. Na seção 3 é delineado a metodologia utilizada. Na seção 4 apresenta os jogos que foram desenvolvidos e os resultados obtidos. Por fim na seção 5 , as considerações finais e em seguida as referências.

\section{O Scratch}

O Scratch é uma linguagem de programação do visual, desenvolvida pelo Media Lab do MIT para auxiliar na aprendizagem. O Scratch foi lançado em 2007 a vantagem de utilizar essa ferramenta é a sua utilização sem conhecimento prévio em uma linguagem de programação. O objetivo é auxiliar a aprendizagem de programação de maneira lúdica e criativa. Possibilita a criação de histórias interativas, animações, simulações, jogos e músicas, e a partilha dessas criações na Web (Maloney et al. 2010).

O Scratch é possível trabalhar os seguintes conceitos de programação: sequência, iteração, condição, variáveis, execução paralela, sincronia, interação em tempo real, 
V Congresso Brasileiro de Informática na Educação (CBIE 2016)

Anais do XXII Workshop de Informática na Escola (WIE 2016)

lógica booleana, números randômicos, tratamento de evento e criação de interfaces (Fagundes, 2008).

\begin{abstract}
Ao criarem seus projetos em Scratch, os jovens aprendem muitas habilidades do século 21 que serão críticas para um futuro de sucesso: pensar criativamente, comunicar-se claramente, analisar sistematicamente, usar tecnologias fluentemente, colaborar efetivamente, projetar iterativamente e aprender continuamente." (Resnick, 2007).
\end{abstract}

Para que os jovens no meio acadêmico possam ser desafiados é preciso ver conforme as observações acima (Resnick, 2007), em que pesquisadores do MIT (Massachusetts Institute of Technology) constataram que os jovens se interessaram por vídeo games, animações, personagens e criação de arte.

O Scratch é programado por meio de blocos em que o usuário escolhe para montar programas. Existem diversos estudos em diferentes projetos contribuindo positivamente com o uso do Scratch para o aprendizado de programação (Venanio, V., 2015) (Salazar et al., 2015) (Muñoz et al., 2015).

\title{
3. Metodologia
}

Este relato de trabalho foi resultado de um trabalho realizado durante a disciplina de introdução à programação no curso de engenharia elétrica. As atividades foram realizadas em uma faculdade particular, onde estavam cursando a disciplina 40 alunos. Durante a disciplina, alguns alunos deixaram de comparecer, totalizando 32 alunos que chegaram ao fim da disciplina e desenvolveram o projeto proposto pela disciplina.

A disciplina teve um total de 30 encontros sendo um encontro semanal com uma carga horária de 2 horas/semana, totalizando um total de 60 horas de conteúdo. As aulas eram realizadas no laboratório de informática e os alunos trabalharam durante a disciplina em dupla. As aulas tinham um caráter teórico/prático, onde os estudantes eram estimulados a resolverem desafios de programação utilizando conceitos de raciocínio e lógica.

Para realizar a avaliação dos alunos e para que a disciplina se fosse mais atrativa despertando do estudante em continuar, foi proposto a criação de jogos que estejam correlacionadas com a área da engenharia elétrica, mesmo considerando que os alunos não possuindo conhecimento avançados em programação e game designer.

Para subdividimos, para questões de simplificação, o trabalho em quatro etapas que são descritas abaixo:

\subsection{Etapa 1}

A etapa 1 correspondeu na divisão dos grupos de trabalho. Cada grupo de trabalho ficou responsável em criar um blogger para que todas as dificuldades, melhorias e ideias fossem registradas. Foi feito um brainstorm para definição dos temas dos jogos de cada equipe de forma autônoma.

Foram divididos um total de 8 grupos. O estudo buscou verificar a aprendizagem, desenvolvida pelos grupos por meio dos jogos digitais na área da 
V Congresso Brasileiro de Informática na Educação (CBIE 2016)

Anais do XXII Workshop de Informática na Escola (WIE 2016)

engenharia elétrica, que os estudantes desenvolveram de forma a atender aos objetivos proposto da disciplina de introdução à programação.

\subsection{Etapa 2}

A etapa 2 correspondeu o desenvolvimento do document game designer (GDD), os grupos se reunirão para planejar o jogo para isso foi utilizado a metodologia de trabalho que é o GDD. É definido como:

Trata-se um documento de texto, em geral bem ilustrado, concebido por um game designer e que descreve diversos elementos de um jogo, como estética, narrativa, mecânicas, etc, tendo a função de comunicar e guiar os diversos envolvidos no processo de desenvolvimento do jogo (Novak, 2007 apud Motta, Junior, 2013).

O GDD é uma ferramenta textual produzida por um game designer que descreve todas as características de um jogo. Essa parte foi importante para que o grupo elaborasse todas as informações do jogo desde os conceitos, personagens, cenários, níveis, sons e as regras do jogo. Uma grande facilidade foi encontrar diversas imagens e sprites na própria biblioteca do Scratch.

\subsection{Etapa 3}

Nesta etapa os estudantes, iniciaram o desenvolvimento do código do jogo. Durante essa etapa foi programado o jogo, utilizando a ferramenta Scratch, e por meio da programação em blocos, sprites disponíveis, cenários e outras imagens disponíveis que a ferramenta disponibiliza.

Também nessa etapa foi realizado os testes do jogo e disponibilizado por meio do blogger do grupo o jogo desenvolvido para continuidade e aperfeiçoamento futuramente do trabalho.

\subsection{Etapa 4}

Finalmente na última etapa os estudantes apresentaram o jogo desenvolvido por meio de um workshop que foi organizado na disciplina no final do semestre. Durante a apresentação os grupos apresentaram seus jogos e o blogger com todo trajeto que tiveram até chegar em uma versão final.

\section{Resultados e Jogos Desenvolvidos}

O trabalho resultou, nos jogos que foram publicados pelos estudantes. Dos oito trabalhos desenvolvidos na disciplina será apresentado aqui 4 deles que foram escolhidos de forma aleatória com a finalidade de apresentar os resultados desenvolvido no final da disciplina.

\subsection{Jogo de Raquete}

Foi desenhado uma mesa de tênis contendo uma bola e duas raquetes conforme mostra a figura 1, com o objetivo de dois jogadores rebaterem a bola até que no erro do adversário o outro jogador faça uma pontuação. 
V Congresso Brasileiro de Informática na Educação (CBIE 2016)

Anais do XXII Workshop de Informática na Escola (WIE 2016)

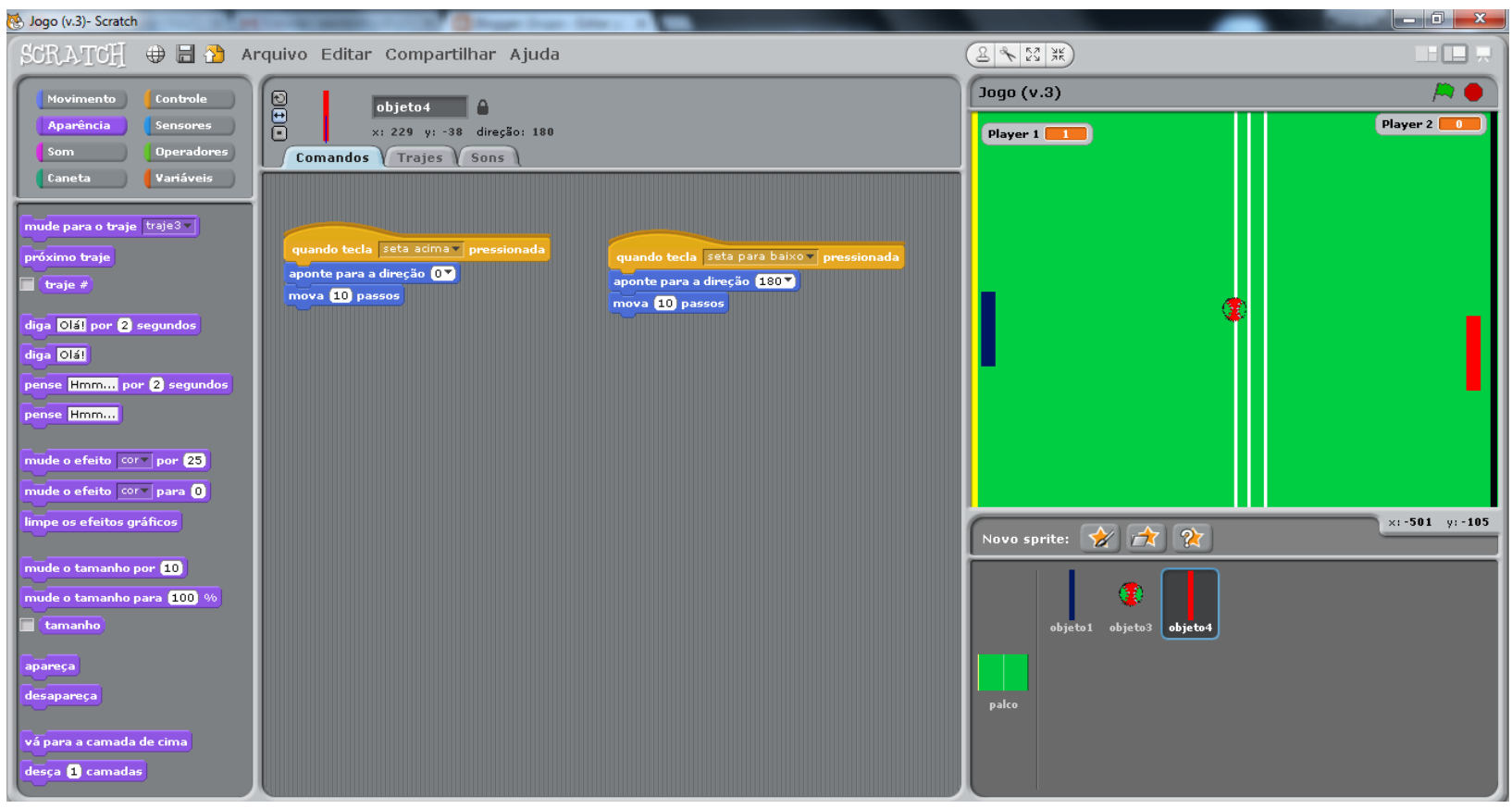

Figura 1 - Jogo de Raquete

Foram feitas a programação para o uso das raquetes e da bola. As raquetes são movimentadas por meio de comandos no teclado com o intuito de atingir a bola antes que tocasse na borda da quadra. Para pontuar é necessário que o oponente não consiga rebater a bola lançada ou rebatida. Assim que isso acontece, é computada em um placar a pontuação do jogador.

Na medida em que alcança uma vantagem de determinado número de pontos em relação ao oponente, muda-se o cenário do jogo iniciando uma nova fase, que pode ser apresentada de maneira mais rápida os lançamentos da bola.

\subsection{Jogo Eletroman}

A ideia do trabalho consiste, basicamente, em criar um jogo de plataforma em que o personagem principal (Eletroman) que é controlado pelo jogador, este sprite foi criado a partir de peças eletrônicas de um computador (figura 2). $\mathrm{O}$ objetivo seria sobreviver o maior tempo possível esquivando da água e ultrapassar o recorde do jogador anterior. Terá também outros personagens eletrônicos que serão inimigos e atacaram pelos lados, aumentando a dificuldade do jogo, além do player agir de maneira mais ágil.

Um curto-circuito ocorre quando a corrente elétrica atravessa um condutor ou um dispositivo com resistência desprezível, causando um superaquecimento. Embora a água destilada (sem a presença de impurezas ou sais minerais) não conduza eletricidade, ao ser misturado com outras substâncias ela passa a conduzir corrente elétrica. 
V Congresso Brasileiro de Informática na Educação (CBIE 2016)

Anais do XXII Workshop de Informática na Escola (WIE 2016)

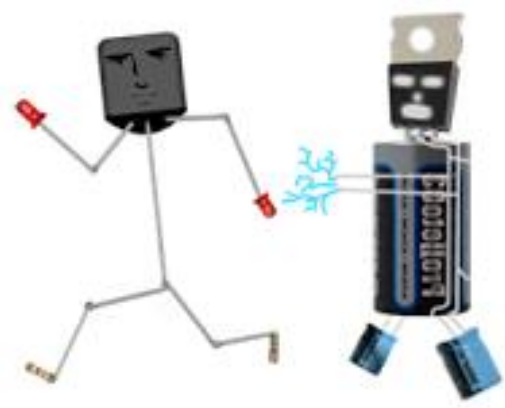

Figura 2 - Storyboard dos personagens

O personagem é formado por um gabinete aberto. O cenário foi projetado com uma placa mãe de computador (figura3). O Jogo inicia quando está ocorrendo uma chuva e a água se infiltra na máquina e começa a pingar gotas de água em seu interior, dando início ao jogo. O objetivo é esquivar dos pingos e água e conseguir o maior número de pontos possível.

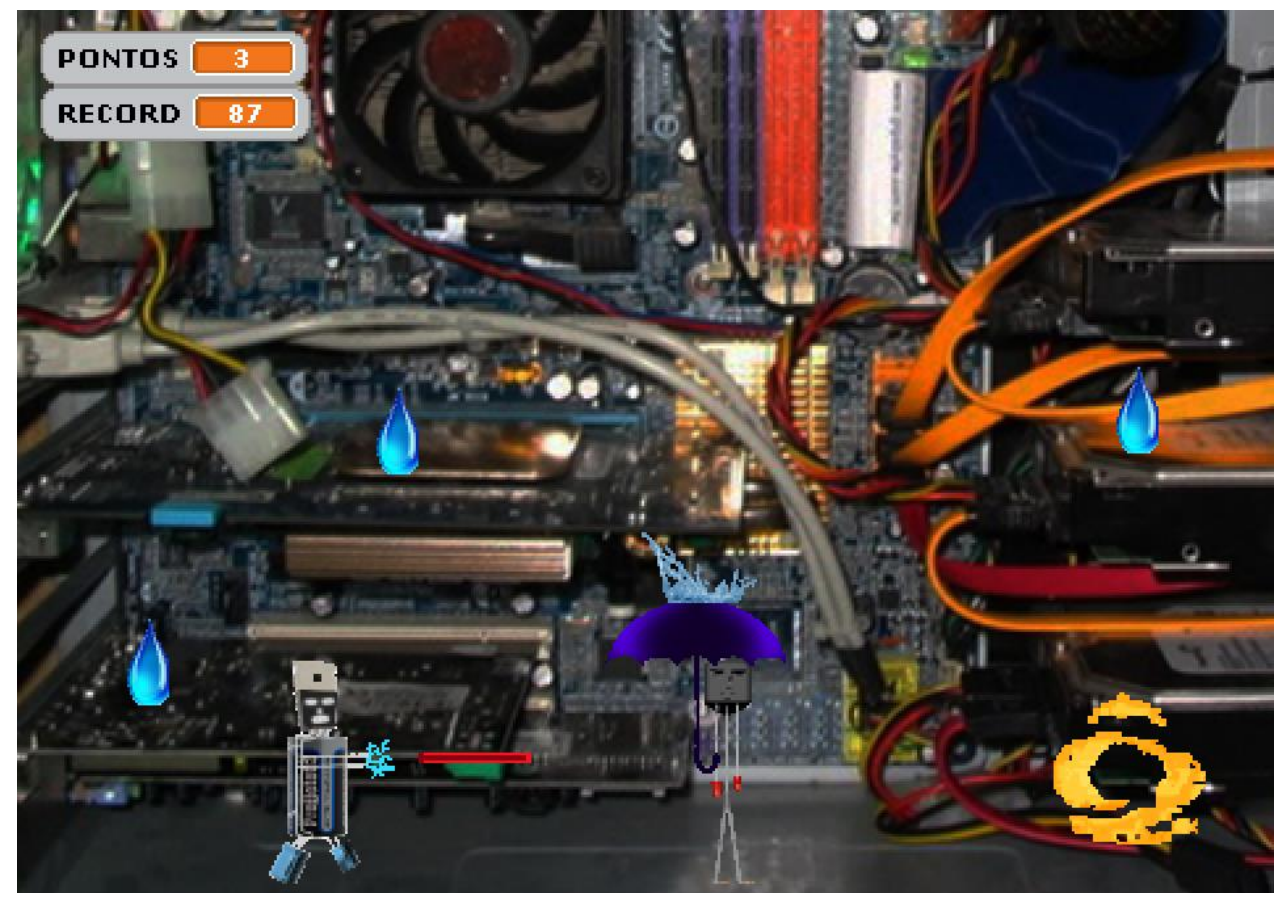

Figura 3 - Cenário principal do jogo Eletroman

\subsection{Jogo da Memória}

O jogo da memória é um tipo de game tradicional, porém as peças utilizadas neste foram símbolos da engenharia elétrica (figua 4). Durante o jogo as peças apresentam uma figura em um dos lados. Cada figura se repete em duas peças diferentes. Para começar o jogo, as peças são postas com as figuras e voltadas para baixo.

O jogo foi programado no Scratch de maneira single player. O jogo termina quando todos os pares de cartas são descobertos e o tempo finaliza. Fica registrado o recorde do jogador que realizar de maneira mais rápida. As posições das peças são modificadas toda vez que iniciar o jogo. 
V Congresso Brasileiro de Informática na Educação (CBIE 2016)

Anais do XXII Workshop de Informática na Escola (WIE 2016)

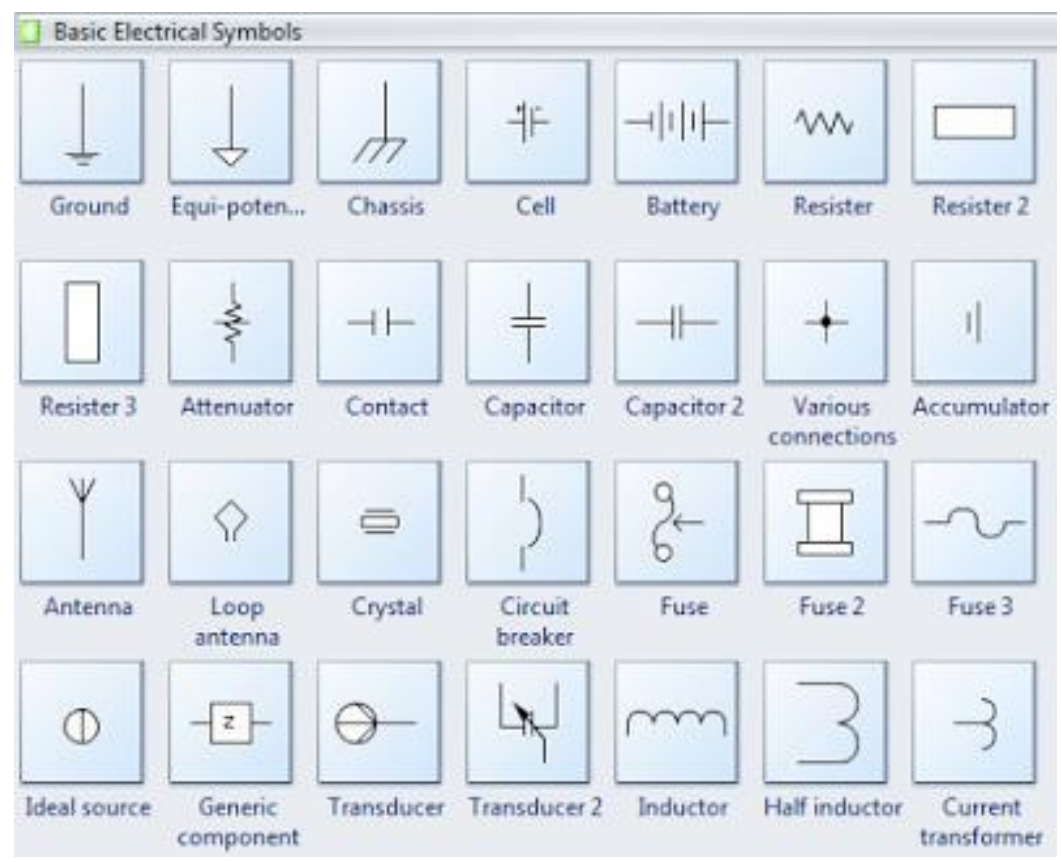

Figura 4 - Símbolos da Engenharia Elétrica

\subsection{Jogo o Labirinto Jigsaw}

Este jogo foi desenvolvido baseado em um labirinto, que consiste em resgatar uma personagem "princesa", tendo no jogo os obstáculos que geram a dificuldade. O jogo foi desenvolvido na ferramenta Sratch, é o objetivo é reforçar o aprendizado sobre cálculo aplicado, já que existe diversas questões para serem solucionados durante o jogo.

No labirinto Jigsaw (figura 5), você irá resolver alguns cálculos básicos de logaritmos, funções quadráticas e funções do segundo grau. O personagem principal e o nosso já famoso conhecido o "Super Mário" sua missão e recolher os objetos "bananas" no labirinto as quais estão vinculadas a questões de cálculo a serem respondidas para que seja computado a pontuação.

O jogo foi elaborado para reforçar os conhecimentos básicos de engenharia na parte de introdução ao cálculo e também trabalhar a habilidade de pensar e tomar decisão de maneira mais ágil. Este jogo tem por objetivo estimular o raciocínio lógico, analítico, coordenação, memória de trabalho e pensamentos. $\mathrm{O}$ player tem a oportunidade de experimentar conceitos aprendidos, interpretação de questões e resoluções de problemas. No jogo é possível ser cadastrado previamente e são embaralhadas toda vez que se inicia o jogo. 


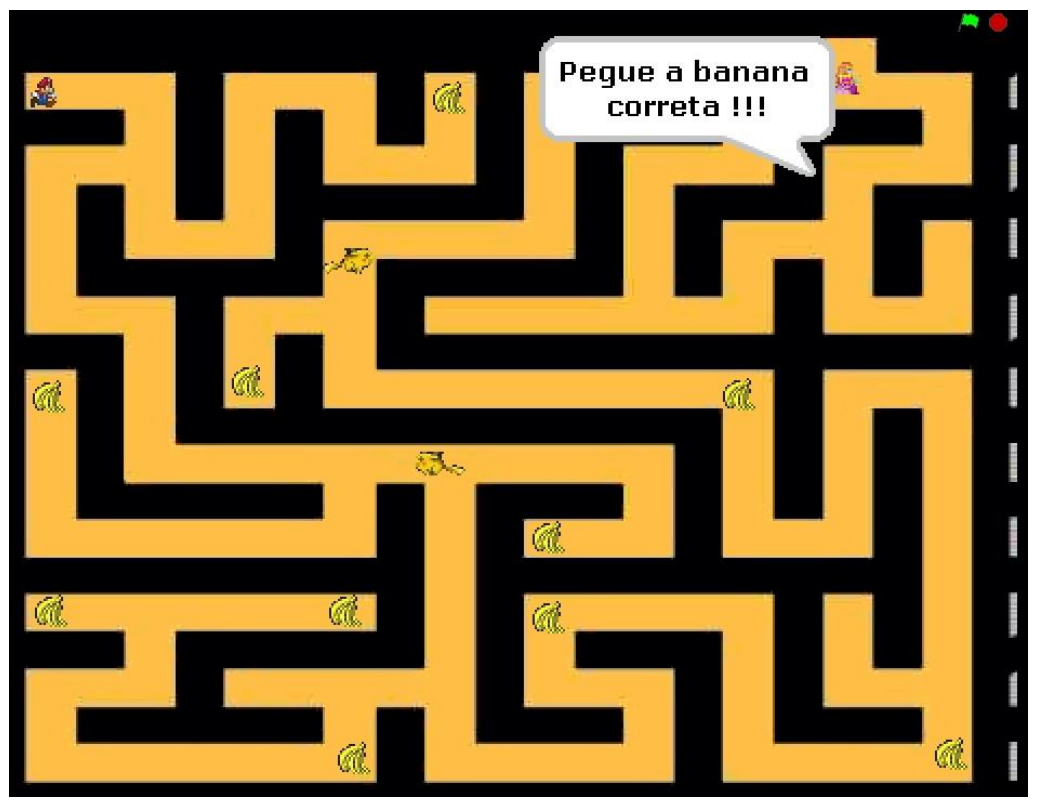

Figura 5 - Cenário do Jogo do Labirinto

\section{Considerações Finais}

Este trabalho apresentou o uso de criação de jogos digitais na disciplina de introdução à programação utilizando a ferramenta Scratch. Durante as aulas foi possível perceber um grande interesse da turma pelo tema de "criação de jogos", além de não precisar de não ter conhecimento a princípio em programação.

Por certo a utilização das tecnologias da comunicação e informação pode ajudar consideravelmente o apoio no ensino de programação. Propusemos neste trabalho, visando a facilidade e a interdisciplinaridade das áreas da engenharia elétrica no desenvolvimento do jogo. Os jogos que foram aqui desenvolvidos estão disponíveis livremente no site da disciplina $<$ https://sites.google.com/site/novomilenio2016x01/introducao-a-computacaoengenharia-eletrica $>$ e também disponível na biblioteca de projetos do site do MIT Scratch como objetos de aprendizagem que podem ser utilizados livremente pela comunidade.

Por meio deste artigo percebemos que trabalhar utilizando a ferramenta Scratch como abordagem alternativa no processo de aprendizagem, aliado com uma maneira lúdica desenvolvendo jogos digitais. A partir deste trabalho os alunos são capazes de desenvolver jogos para auxiliar outras disciplinas.

\section{Referências}

Fagundes, L. C.; Voelcker, M. Dieterich; Seidel, S. Fluência digital e Ambientes de Autoria Multimídia. CINTED-UFR GS. Novas Tecnologias na Educação. Rio Grande do Sul, 2008. v. 6. n⿳⺈⿴囗十

Gee J. P. (2003) What Video Games Have to Teach Us About Learning and Literacy. ACM Computers in Entertainment, Vol. 1, No. 1, BOOK 1. 
V Congresso Brasileiro de Informática na Educação (CBIE 2016)

Anais do XXII Workshop de Informática na Escola (WIE 2016)

Gee, J. P. (2009). Deep Learning Properties of Good Digital Games How Far Can They Go? Theories and Mechanisms: Serious Games for Learning. New York.

Jenkins, T. (2001). The motivation of students of programming. In ACM SIGCSE Bulletin, volume 33, pages 53-56. ACM.

Kölling, M., Koch, B., e Rosenberg, J. (1995). Requirements for a first year objectoriented teaching language, volume 27. ACM.

Maloney, J., Resnick, M., Rusk, N., Silverman, B., and Eastmond, E. (2010). The scratch programming language and environment. ACM Transactions on Computing Education (TOCE), 10(4):16.

Muñoz, R., Barcelos, T., Acevedo, R V., Silveira, I. F., Diseño e Implementación de un Taller de Programación de Juegos Digitales con Scratch como Apoyo a Fundamentos de Programación. Anais do IV Congresso Brasileiro de Informática na Educação CBIE-LACLO, 2015.

Motta, R. L., Junior, J. T., Short game design document (SGDD). SBC - Proceedings of SBGames 2013. Art \& Design Track.

Novak, J. Game Development Essentials. Delmar Carnage Learning, 2007.

Piaget, J. (1951). A formação do símbolo na criança. Zahar Editores, Rio de Janeiro.

Prensky, M. (2003). Digital game-based learning. Computers in Entertainment. Editora: McGraw-Hill. University of Califórnia.

Scratch (2016). Disponível em <https://scratch.mit.edu/> Acessado em 13/06/2016.

Salazar, R.; Odakura, V.; Barvinki, C. Scratch no Ensino Superior: Motivação Anais do III Congresso Brasileiro de Informática na Educação - CBIE-LACLO, Alagoas 2015.

Venancio, V. A leitura do software de programação Scratch realizada pelo professor: uma pesquisa em ação. Anais do IV Congresso Brasileiro de Informática na Educação - CBIE-LACLO, 2015. 